\title{
"I'll Never Forget This": Evaluating a Pilot Workshop in Effective Communication for Dental Students
}

\author{
Henriette Lucander, M.S.; Kerstin Knutsson, Ph.D., D.D.S.; Hanna Salé, Ph.D., D.D.S.; \\ Anders Jonsson, Ph.D.
}

Abstract: This study evaluated a pilot workshop for teaching communication skills to dental students. The methodology is based on an experiential learning approach, the use of realistic clinical scenarios, simulated patients, and an integrated teaching team of both educational researchers and dentists. Furthermore, the methodology was adapted for short workshops, which is thought to offer better possibilities for frequent and effective training of communication skills throughout the curriculum. The workshop was piloted with groups of six to ten students from the sixth and tenth semesters $(n=94)$. Results show that the majority of students found the tasks meaningful and well aligned with how they perceived their future profession as dentists. Most students also thought that they learned from the task. An interesting finding is that students not only found it instructive to practice how to communicate in authentic situations, but that they generally found the workshop to be thought-provoking while at the same time providing structure and intellectual tools for the future. A possible explanation for this finding is the sharing of explicit criteria for high-quality communication.

\begin{abstract}
Ms. Lucander is Lecturer in Media Technology, School of Technology, Malmö University, Sweden; Dr. Knutsson is Professor of Odontological Diagnostic Radiology, Faculty of Odontology, Malmö University, Sweden; Dr. Salé is Oral and Maxillofacial Radiologist, Faculty of Odontology, Malmö University, Sweden; and Dr. Jonsson is Educational Researcher, Centre for Profession Studies, Malmö University, Sweden. Direct correspondence and requests for reprints to Ms. Henriette Lucander, Malmö University, School of Technology, SE-205 06 Malmö, Sweden; 0046-40-6657241 phone; 0046-40-6657706 fax; henriette.lucander@mah.se.
\end{abstract}

Keywords: communication, dental education, dental students, dentist-patient relations, patient simulation, program evaluation

Submitted for publication 10/4/11; accepted 1/2/12

1 ccording to a large Swedish survey, communication is the most crucial factor affecting how satisfied patients are with health care. Those who have experienced situations of poor communication refrain from seeking health care to a much larger extent than those who have more positive experiences. ${ }^{1}$ In Swedish dental education, however, learning how to communicate with patients is not always prioritized. A similar situation was reported from a survey of forty U.S. and Canadian dental schools, in which the teaching of communication skills is often not well integrated into the curriculum, does not include any theoretical background, is taught mostly using passive learning techniques, and does not include adequate student evaluation. ${ }^{2}$ Furthermore, there seems to be a relative lack of published work on communication skills in dental education as compared to medical and nursing education, where the amount of curricular time devoted to communication, including the assessment of clinical performance, has been reported to increase in recent years. ${ }^{2-6}$

Due to the perceived importance of communication skills in combination with the lack of adequate teaching strategies of these skills, a workshop for teaching communication skills to dental students was piloted and evaluated in this study. The study is part of a larger project that intends to develop a methodology for not only teaching these skills but assessing students' communication skills as part of their professional development.

\section{Teaching Communication Skills}

Although defined slightly differently in different studies, communication skills for professional dentists include the ability to express themselves clearly, to use language that patients can understand, to listen to their patients, and to involve patients in treatment decisions. ${ }^{7}$ A problem, however, is that while it may be quite easy to comprehend criteria for successful communication, actually using communication skills in clinical situations may be much more difficult. This is partly because skillful communication involves not only verbal but also nonverbal communication acts, such as body language, written communication, and pictures (e.g., dental radiographs). ${ }^{7}$ 
How, then, can communication skills be taught effectively? According to Aspegren, who conducted a review of research about teaching and learning communication skills, the teaching of such skills should be experiential as it has been shown conclusively that instructional methods do not give the desired results. ${ }^{4}$ However, attempts to use clinical skills assessments such as objective structured clinical examinations (OSCEs) for this purpose in dental education have not necessarily led to desirable results. The brief communication skills training described by one group of researchers as "one-shot faculty-facilitated" was not sufficient to improve dental students' communication skills; instead, those authors suggested that a comprehensive training course would likely be more beneficial. ${ }^{8}$ Such a course was described by Hannah et al.: in it, sixty-seven third-year dental students participated in a communication skills course consisting of four two-hour classes. ${ }^{9}$ That course made use of simulated patients, case-based scenarios, videotaped interviews, and class role-plays, and the students rated the course very highly. Furthermore, the students considered communication skills to be a significantly more important component of their education after completion of the course.

One of the main reasons for the positive evaluations in the study by Hannah et al. ${ }^{9}$ is thought to be that the students found the clinical scenarios and the opportunity to practice skills with simulated patients a realistic and challenging learning task. Some students commented that they had encountered similar situations and appreciated the opportunity to practice different approaches in a safe setting. Realistic, clinically based scenarios thus seem to be an important component of effective communication skills programs. The use of simulated patients (actors portraying patients) is another.

Although this program was considered very successful, improvements can always be made, and Hannah et al. suggested that the large group size (sixteen or seventeen students) may have led to lower ratings of tutor sensitivity to students' needs, concerns, and progress than anticipated. ${ }^{9}$ Furthermore, in that study, students were asked to perform in front of their classmates. The authors suggested that it might be better for each student to be videotaped communicating with patients in the absence of their classmates since some students reported that it was difficult to concentrate on the patient with an audience present.

Other potential problems not raised by Hannah et al. ${ }^{9}$ are the fact that small-group training requires a huge workload for faculty and that although com- munication skills can be taught in courses and are indeed learned there, such skills have been found to be easily forgotten if not maintained by practice. . $^{410}$ Deveugele et al. therefore suggested that communication skills need to be practiced throughout the entire curriculum since practice every year seems to lead to better acquisition. ${ }^{10}$ As a consequence, smaller but recurring workshops on communication skills might be more effective in a longer perspective. Research in medical education has found that significant improvements in communication (such as reduced verbal dominance, increased use of open-ended questions, and increased use of empathy) can follow from short teaching interventions (a total of four hours) based on videotaped interviews with simulated patients and individualized feedback. ${ }^{11}$

Building on experiences from these previous studies, our study aimed to pilot and evaluate a methodology in which dental students are taught communication skills during a short workshop based on communication events with simulated patients. Through the use of short workshops as opposed to full courses used by Hannah et al., ${ }^{9}$ the methodology may provide better opportunities for frequent and effective training of communication skills throughout the curriculum. Such a format also means that students have the possibility of practicing their communication skills in various subject areas.

\section{Methods}

A workshop on communication skills was piloted during the spring semester of 2011 at the Faculty of Odontology at Malmö University, Sweden, with students from the sixth and tenth semesters (fortyeight and forty-six students, respectively). For the sixth-semester students, the workshop was a compulsory component of a course on oral and maxillofacial radiology, while for the tenth-semester students it was introduced as an extracurricular activity (nevertheless, 80 percent of the students participated). In both groups, the workshop was conducted in small groups of six to ten students.

Overall, the workshop lasted for approximately three hours, and each group was tutored by two educational researchers with the assistance of one of the students' regular teachers in oral and maxillofacial radiology. All tutors involved were employed at the university, and the workshops were carried out within their respective appointments. A list of quality criteria for skillful communication, adapted from 
assessment instruments used in medical education ${ }^{12,13}$ and validated though discussions with the teachers in oral and maxillofacial radiology (odontology), was handed out to the students at the beginning of the workshop. The purpose of handing out the criteria was to communicate expectations to the students and to provide them with a tool of thought to guide their learning (see Table 1).

Each assignment was structured by first presenting a situation to the students, which the students had to describe as objectively as possible, without interpretation or bias. For all groups, this first situation was presented as a short movie sequence showing a dentist who had just finished a clinical examination of a new patient. The dentist in the movie suggested that no dental radiographs should be taken this time because the ones from last year's clinical exam were available. However, the patient felt very uncomfortable with this decision since her former dentist had taken radiographs annually. For the tenth-semester students, the second situation was presented as a radiograph showing a case of apical periodontitis. All groups also had the opportunity to add further situations, which some but not all groups did.

After describing the situation, the students analyzed the situation individually and also suggested measures to be taken. These measures were then to be communicated to a patient, who was role-played by one of the educators. Since the same educator also acted in the movie, the situation could go almost seamlessly from the movie into a role-play. The role-play situation allowed the students to try out different communication strategies and evaluate the effect. Some students took turns acting, while the

\section{Table 1. Criteria for effective communication by dental students in clinical training}

Criterion Description

1. Description

2. Analysis

3. Communication

3.1 Information-sharing

3.2 Eliciting information from patient

3.3 Reaching agreement

3.4 Providing closure

4. Reflection
The student ...

... describes the situation without prejudice and in relevant detail.

... analyzes the situation from the perspective of all of those involved: why do they act as they do?

... suggests professional actions to be taken in order to handle the situation.

... discusses potential consequences of the proposed actions.

... argues for an appropriate solution to the situation.

... recognizes the patient's preferred (or current) mode of communication and selectively chooses the most effective mode of communication for the situation.

... explains using words that patient can understand (i.e., no use of confusing terms or jargon-laden language).

... assesses the patient's understanding of problem by using both open and closed questions as appropriate.

... demonstrates effective listening in a way that the patient feels heard and understood (i.e., uses nonverbal cues such as nodding, pausing, maintaining eye contact, and verbal skills including back-tracking, reflecting, and mirroring).

... takes the patient's perspective into consideration, including the patient's individual concerns, beliefs, and expectations.

... respects the patient's cultural and ethnic beliefs, practices, and language.

... tackles personal questions sensitively.

$\ldots$ asks if patient has any questions.

... includes the patient in choices and decisions to the extent $s /$ he desires.

... checks for mutual understanding of diagnostic and/or treatment plans.

... asks about the patient's ability to follow diagnostic and/or treatment plans.

... summarizes the session.

... asks if the patient has any further questions, concerns, or other issues.

... sets the agenda for follow-up encounters in collaboration with the patient.

... clarifies contact arrangements.

... identifies own strengths and areas in need of further development in his or her analytical and communication skills.

... suggests improvements to his or her own performance.

Source: Adapted from Humphris GM, Kaney S. The objective structured video exam for assessment of communication skills. Med Educ 2001;34(11):939-45; and Rider EA, Keefer CH. Communication skills competencies: definitions and a teaching toolbox. Med Educ 2006;40(7):624-9. 
other students watched and commented on how the situation could be improved. Although acknowledging that some students may experience difficulties concentrating on the patient with an audience present (as found by Hannah et al. ${ }^{9}$ ), this design was used to provide timely feedback to the students. Immediate feedback has been shown to be more effective for learning than delayed feedback for new and difficult tasks, and there is also wide support for using immediate feedback to promote learning and performance on verbal and procedural tasks. ${ }^{14}$ Recording students' performance in isolation, in order to watch the movies and give feedback afterwards, might therefore not have the same impact on student learning.

After each role-play, the students analyzed the communication events with the aid of the criteria mentioned, in order to identify strengths and weaknesses in the interaction. The students were also prompted to reflect on their own strengths and weaknesses in terms of communication skills and what they thought was needed in their education to address these weaknesses.

At the end of the workshop, the students evaluated it. A five-point rating scale was utilized, from 1 (low) to 5 (high) for some questions, along with some open-ended questions (Table 2). It should be noted that the workshop was entirely learning-focused and the students were not graded. The students were informed about the purpose of the workshop, and their consent was given by completing the course evaluation form.

Frequency tables were generated for the ratingscale questions in order to analyze the students' ratings. For each question, median and median absolute deviation (which is equivalent to standard deviation for ordinal scales) were calculated. Ratings from the sixth- and tenth-semester students were compared using a median test in order to investigate whether there was a significant difference between the two groups for $\mathrm{p}=0.01$.

\section{Results}

All of the students who participated in the communication skills workshop completed the evaluation questionnaire (i.e., 100 percent), although one student answered only the open-ended questions. Most students found the tasks meaningful and well aligned with their future professional role as a dentist (the percentage of students giving these questions a rating of 4 or 5 was over 90 percent) (Table 2). Most students thought that they learned from the task and the criteria were useful for them. The lowest rating was for how typical they thought the situations were (median=3). The MAD values shown in Table 2 demonstrate that students' ratings were clustered around the medians, which means that the dispersion was low. A median test was performed, comparing the ratings of students from different semesters, and a significant difference between semesters was only found for one variable. Students in the tenth-semester group felt significantly more prepared for the task than the sixth-semester students $(\mathrm{p}<0.01)$.

The students were also asked to give openended written feedback in relation to each ratingscale question, as well as about things that could be improved in the workshop design. The results from those questions showed that students generally found the criteria useful because they clarified expectations

Table 2. Percentage of students who rated the workshop on the highest two categories on the rating scale and median and median absolute deviation (MAD) of student ratings

$\begin{array}{lcc} & \begin{array}{c}\text { Percentage That } \\ \text { Rated Workshop } \\ 4 \text { or } 5(\mathrm{n}=93)\end{array} & \begin{array}{c}\text { Median } \\ (\text { MAD) } \\ (\mathrm{n}=93)\end{array} \\ \text { Question } & 73.1 \% & 4(1) \\ \text { 1. To what extent did you feel prepared for the task? } & 58.1 \% & 4(1) \\ \text { 2. To what extent did you find the criteria useful? } & 91.3 \% & 5(0) \\ \text { 3. To what extent do you think that the tasks were aligned with your future role as a dentist? } & 44.6 \% & 3(1) \\ \text { 4. How typical do you think that the situations are for professional dentists? } & 90.2 \% & 5(0) \\ \text { 5. To what extent do you think the task is meaningful for your future profession? } & 71.8 \% & 4(0) \\ \text { 6. To what extent do you think that you learned from the task? } & \text { N/A } & \text { N/A } \\ \text { 7. Is there anything that you would like to change? } & \text { N/A } & \text { N/A }\end{array}$

Note: The rating scale ranged from 1 (low) to 5 (high). Questions 1-6 had combinations of rating-scale and open-ended questions, while questions 7 and 8 were only open-ended. One student did not answer questions 3-6; for those questions, n=92. 
and facilitated reflection. As one student expressed it, "They provided a good structure. It felt like I read them as a guide for how to communicate, like notes from a good lecture."

The students were asked how well aligned they thought the tasks were with their future profession and how typical they thought the situations were. Several students thought the situation in which the patient felt uncomfortable with the decision not to take any $\mathrm{x}$-rays was a bit extreme and that it was unrealistic to enter the situation after the clinical examination. Still, they acknowledged that similar situations could occur (some students wrote that they had already encountered comparable situations), and although it may not be very frequent, they found the task meaningful as a starting point for discussion and reflection.

Many students found the workshop to be both instructive (i.e., to be given practice in how to communicate) and thought-provoking. As one student commented, "I see communication in a new light. Things you did not notice before are obvious now." Even if most students found the workshop instructive, a small number did not (ten students gave this question a low rating of 1 or 2). As can be seen in the answers from these students, they did not perceive that they learned much either because they felt they knew all about these things before or because they did not think that such personal abilities could be learned from instruction. One student expressed it like this: "It is difficult to learn practical things in an artificial situation; such things are more appropriately learned in the clinic."

When asked how to improve the workshop, a few suggestions were made. Some students suggested they should not write down their reflections but should concentrate on the discussion and that they should be provided with more background information about the patient before acting in the role-play. Most students, however, answered that the workshop needed no improvements. Instead, what they wanted was more frequent workshops of a similar kind, each with a larger number of role-plays and earlier in the program. Furthermore, many students wrote that it was a fun way to learn and that it was a good idea to use educationally skilled instructors together with experts from the dental profession. Obviously, the students were satisfied with the quality of the workshop but not with the quantity.

\section{Discussion}

The aim of this study was to evaluate a pilot workshop for teaching communication skills to dental students. The methodology, which built on studies in both medical and dental education, was based on an experiential-learning approach, realistic clinical scenarios, simulated patients, and an integrated teaching team. ${ }^{9}$ Furthermore, the methodology was adapted for short workshops, which are thought to provide better possibilities for frequent and effective training of communication skills throughout the curriculum, as opposed to being limited to a single course and therefore more easily forgotten.

The results showed that the majority of the students found the tasks meaningful and well aligned with their future profession as dentists, although many did not think that the situations were all that typical. Most students also thought they learned from the task and that the criteria were useful for them. The fact that students rated most items highly and that they seemed to appreciate the workshop is consistent with evaluations of previous studies reporting the teaching of communication skills. ${ }^{9,15,16}$ As also seen in the results, the students generally seemed to agree on most points in the evaluation, and the students' ratings across semesters were in accordance with each other. The only exception to the agreement across semesters was that the tenth-semester students felt more prepared for the task than the sixth-semester students due to their greater clinical experience.

Similar to the findings reported by Hannah et al., ${ }^{9}$ a main reason for the positive evaluations seems to be that the students found the clinical scenarios authentic and meaningful. Other success factors appeared to be the use of a teaching team consisting of professionals from both the educational and dental sciences. As noted by Hannah et al., ${ }^{9}$ this combination allowed for feedback from various areas of expertise and the possibility of answering a wider range of questions during group discussions.

A small number of students did not find the workshop very instructive, either because they felt that they already knew the content or because they did not think such skills could be learned from instruction. Hannah et al. ${ }^{9}$ also found initial skepticism among the students in their study, which they attributed to the use of the term "communication skills" - a phrase that might lead students to think they will be learning skills they already possess or skills acquired intuitively or through common sense. 
Hannah et al. thought this skepticism may have been due to the students' lack of appreciation of the distinct nature of communication skills in clinical settings and that they placed professional communication on a par with everyday conversation. Since the same tendency was seen in our study, although only with a small number of students, there may be a need to explicitly highlight the differences between ordinary conversations and professional communications in order to motivate these students to practice their skills. This could be done theoretically (for instance, by comparing patterns of everyday dialogues with criteria for communications skills) or practically (for instance, by systematically exploring consequences of various modes of communication in simulated situations). There might also be a need to explicitly address the question of professional learning with the students, perhaps by discussing the role of language and reflection in the learning of tacit knowledge.

There were some severe limitations to this study, such as it being a pilot implementation in a single institution with a small sample size; nevertheless, there were clear indications that most students appreciated the workshop as a tool for reflection. They also realized that they needed recurrent practice and that a single workshop was not enough to provide this. As a consequence, they reported that they would like more frequent workshops during their entire dental education and dealing with a wider range of situations.

To implement the workshop as a recurring event, which is very consistent with the intentions of this project, the next step will be to establish standards for communication skills. This can be done by analyzing and comparing through video analysis the performance of sixth- and tenth-semester students. These standards can then be used to track the progress of students during their education, but also to evaluate the efficacy of this and future workshops on communication skills - for instance, through pre- and post-tests or comparison groups. To perform such an evaluation is seen as extremely important, since it is not satisfactory to rely entirely on students' perceptions of learning, which is what was investigated in this study. Instead, there is a need to investigate whether (and to what extent) workshops such as this do indeed aid students in developing the desired skills and learning outcomes and which changes could make them even more effective. This is not to say, however, that students' perceptions are unimportant. On the contrary, that the students perceive the workshop as meaningful is a necessary - although not sufficient - condition for successful learning, and the positive evaluations by the students therefore suggest it is worthwhile to further develop this workshop design.

\section{REFERENCES}

1. Olsson M. Nya tider medför nya krav på läkarna [New demands on physicians in the future]. Pharm Industry 2009;12(4):62-4.

2. Yoshida T, Milgrom P, Coldwell S. How do U.S. and Canadian dental schools teach interpersonal communication skills? J Dent Educ 2002;66(11):1281-8.

3. Fernandez A, Wang F, Braveman M, Finkas LK, Haue KE. Impact of student ethnicity and primary childhood language on communication skill assessment in a clinical performance examination. J Gen Intern Med 2007;22(8);1155-60.

4. Aspegren K. BEME guide no. 2: teaching and learning communication skills in medicine - a review with quality grading of articles. Med Teach 1999;21(6):563-70.

5. Nestel D, Betson C. An evaluation of a communication skills workshop for dentists: cultural and clinical relevance of the patient-centered interview. Br Dent J 1999; 187(7):385-8.

6. Association of American Medical Colleges. Contemporary issues in medicine: communication in medicine. Washington, DC: Association of American Medical Colleges, 1999.

7. Hobgood CD, Riviello RJ, Jouriles N, Hamilton G. Assessment of communication and interpersonal skills competencies. Acad Emerg Med 2002;9(11):1257-69.

8. Cannick GF, Horowitz AM, Garr DR, Reed SG, Neville BW, Day TA, et al. Use of the OSCE to evaluate brief communication skills training for dental students. J Dent Educ 2007;71(9):1203-9.

9. Hannah A, Millichamp J, Ayers KM. A communication skills course for undergraduate dental students. J Dent Educ 2004;68(9):970-7.

10. Deveugele M, Derese A, De Maesschalck S, Willems S, Van Driel M, De Maeseneer J. Teaching communication skills to medical students: a challenge in the curriculum? Patient Educ Couns 2005;58(3):265-70.

11. Roter DL, Larson S, Shinitzky H, Chernoff R, Serwint JR, Adamo G, et al. Use of an innovative video feedback technique to enhance communication skills training. Med Educ 2004;38(2):145-57.

12. Humphris GM, Kaney S. The objective structured video exam for assessment of communication skills. Med Educ 2001;34(11):939-45.

13. Rider EA, Keefer CH. Communication skills competencies: definitions and a teaching toolbox. Med Educ 2006;40(7):624-9.

14. Shute VJ. Focus on formative feedback. Rev Educ Res 2008;78(1):153-89.

15. Gorter RC, Eijkman MA. Communication skills training courses in dental education. Eur J Dent Educ 1997;1(3):143-7.

16. Pine CM, McGoldrick PM. Application of behavioral sciences teaching by UK dental undergraduates. Eur J Dent Educ 2000;4(2):49-56. 